\title{
RASGOS DEL EXILIO ITALIANO DE LOS JESUITAS ESPAÑOLES*
}

\author{
POR \\ NICCOLÒ GUASTI \\ Universita' degli Studi di Foggia
}

\begin{abstract}
RESUMEN
En este ensayo se esbozan algunas implicaciones del exilio de los jesuitas españoles en la Italia del siglo XVIII. En primer lugar el autor analiza las causas de los apuros económicos sufridos por los ignacianos antes y después de la supresión canónica. Secundariamente se relaciona la producción cultural y editorial desarrollada por los expulsos, particularmente en la crítica de la «leyenda negra», con la campaña de propaganda promovida por el conde de Floridablanca.
\end{abstract}

PALABRAS ClAVE: Compañía de Jesús, reformismo, Ilustración

\section{SKETCHES ON THE ITALIAN EXILE OF SPANISH JESUITS}

\begin{abstract}
This essay tries to elucidate some aspects of the exile of Spanish Assistance in 18th century Italy. First of all, the author analyses the origins of their economic difficulties before and after the suppression. Secondly he links the cultural and editorial production developed by some Spanish Jesuits, in order to refute the ideological paradigm called «leyenda negra», with the press campaign sponsored by the count of Floridablanca.
\end{abstract}

KEY WORDS: Society of Jesus, 18th century reforms, Enlightenment

Recibido/Received 23-05-2008

Aceptado/Accepted 08-10-2008

* Agradezco a los profesores Jesús Astigarraga e Inmaculada Fernández Arrillaga la paciente revisión de mi texto. 
En este trabajo nos proponemos describir las actividades desarrolladas por los jesuitas expulsos durante su exilio en la Italia de finales del Setecientos: ¿qué ocurrió cuando los expulsos llegaron a Italia? ¿Cómo pudo sobrevivir este grupo de eclesiásticos en el Estado de la Iglesia? ¿Cuales fueron las estrategias utilizadas, particularmente después de la supresión canónica, para integrarse en la sociedad italiana de la época? Y, finalmente, ¿cómo lograron los ex jesuitas españoles salvaguardar la memoria no sólo de su antigua Orden, sino de la Asistencia nacional o, más en concreto, de la Provincia particular a la cual habían pertenecido? Dicho de otro modo, ¿cómo pudo sobrevivir la identidad -sobretodo cultural- del grupo jesuítico español a lo largo de más de cuarenta años de exilio? ¿Qué tipo de relación establecieron con la cultura italiana y europea contemporáneas, particularmente con las Luces?

SOBREVIVIR EN LA ITALIA DEL SETECIENTOS: LOS EXPULSOS ENTRE APUROS ECONÓMICOS Y LA BÚSQUEDA DE UNA NUEVA IDENTIDAD

Los diferentes rasgos de la «irrupción», de acuerdo con la definición de Batllori ${ }^{1}$, de los expulsos en la Italia del Setecientos son ya suficientemente conocidos: entre otros, los incentivos en dinero proporcionados por el Consejo Extraordinario para quienes pidieran la secularización; las huidas de los secularizados de Córcega rumbo a Roma y las gestiones del embajador español Azpuru para acogerlos; así como, finalmente, el sistema logístico -proyectado por Madrid y aplicado por los Comisarios Reales y los de Guerra en el veranootoño de 1768- para organizar el viaje de Córcega al territorio de la República de Génova y desde ésta al Estado de la Iglesia. Además es sabido que, después de un año de difíciles negociaciones diplomáticas entre Madrid, París, Génova y Roma, la prohibición de acoger a los expulsos en el Estado del Pontífice terminó en el verano de 1768: frente a la deflagración de la guerra entre los partidarios de Pasquale Paoli y el Reino de Francia, la secretaría de Estado pontificia concedió su tácita aprobación -la oficial nunca llegó- para que la diplomacia borbónica organizara el transporte hacia los territorios pontificios ${ }^{2}$.

\footnotetext{
${ }^{1}$ M. BATLLORI, La cultura hispano-italiana de los jesuitas expulsos españoles-hispanoamericanosfilipinos, 1767-1814, Madrid, 1966.

2 R. OlaecheA, «En torno al ex-jesuita Gregorio Iriarte hermano del Conde de Aranda», Archivum Historicum Societatis Iesu, XXXIII (1964) 157-234; T. EgIDO, «La expulsión de los jesuitas de España», en R. García VillosladA (ed.), Historia de la Iglesia en España, Madrid, 1979, vol. IV, pp. 745792; I. PINEDO IPARRAGUIRRE, «Los jesuitas en su primer año de expulsión (1767) a la luz de la correspondencia de la Embajada española en Roma», Letras de Deusto, 28 (1998) 211-222; ID., Manuel de Roda. Su pensamiento regalista, Zaragoza, 1983; T. EGIDO y I. PINEDo, Las causas "gravísimas» y secretas de la espulsión de los jesuitas por Carlos III, Madrid, 1994; E. GIMÉnEZ LóPEZ (ed.), Expulsión y exilio de los jesuitas españoles, Alicante, 1997; ID. (ed.), La expulsión de los jesuitas de los dominios 
Desde la Pragmática sanción de 2 de abril de 1767, Carlos III había señalado el Estado de la Iglesia como el destino natural de los religiosos españoles, ya que los manteístas consideraban a los jesuitas (reos de lesa majestad por haber intentado un golpe de Estado con el motín de Esquilache) vasallos de un monarca extranjero, el Pontífice. El mismo texto prohibía de manera tajante a los religiosos abandonar el territorio pontificio.

El primer elemento que se ha de destacar acerca de la llegada a Italia de los jesuitas extrañados es la mala acogida ofrecida por sus cofrades italianos. El general Lorenzo Ricci, de hecho, prohibió a las Provincias italianas acoger en sus estructuras a los expulsos españoles: tampoco el argumento de que ellos venían provistos de una pensión vitalicia convenció al último General de la antigua Compañía para abrir las puertas de los colegios italianos a los hermanos españoles perseguidos por los ministros «jansenistas» y «ateos» de Carlos III. Aunque, en los años posteriores, algunos expulsos consiguieron residir en casas y colegios pertenecientes a la Asistencia italiana, lo hicieron pagando un alquiler. La rigidez del General nacía de una preocupación real, o sea que la repentina llegada de casi cinco mil jesuitas extranjeros generara un colapso económico de la Asistencia italiana y, por consiguiente, de la entera Compañía de Jesús: en los años anteriores ésta había tenido que soportar los dos golpes de la expulsión portuguesa y de la extinción de la Asistencia francesa, mientras ya se esperaban las expulsiones de los jesuitas napolitanos, sicilianos y parmesanos, como efecto de la española. En el caso de los portugueses (y, en forma más reducida, también de los padres franceses que habían rehusado jurar obediencia a los Parlamentos), la Asistencia italiana había tenido que hacerse cargo de su manutención porque Pombal había denegado concederles cualquier vitalicio. Por tanto, los apuros del General tenían una razón económico-financiera muy sólida: esta misma razón había llevado el año anterior al secretario de Estado cardenal Luigi Torrigiani, a prohibir el desembarco de los jesuitas expulsos en Civitavecchia porque, a su parecer, la débil estructura socio-económica del Estado eclesiástico no podía soportar esta masa de «gente ociosa»; y, además, se temía que Carlos III, una vez establecidos los expulsos, pudiese suspender el pago de las pensiones. Con eso no se quiere afirmar que las razones materiales fueran las únicas esgrimidas por el General y por la Asistencia italiana: es posible también que el recuerdo de las viejas polémicas que habían dividido, en

españoles, www.cervantesvirtual.com; ID. (ed.), Y en el tercero perecerán. Gloria, caída y exilio de los jesuitas españoles en el siglo XVIII, Alicante, 2002; J. ANDrÉs-GAllEGo, El motín de Esquilache, América y Europa, Madrid, 2003; N. GuAsti, Lotta politica e riforme all'inizio del regno di Carlo III. Campomanes e l'espulsione dei gesuiti dalla monarchia spagnola (1759-1768), Firenze, 2006; F. BoRJA MEDINA, «Extrañamiento y extinción de la Compañía de Jesús: venturas y desventuras de los jesuitas en el exilio de Italia», en M. MARZAL y L. BACIGALuPo (eds), Los jesuitas y la modernidad en Iberoamérica, 1549-1773, México, 2007, pp. 450-492. 
tiempos del General Acquaviva, la Asistencia italiana y la española haya influido en la dura decisión de Ricci ${ }^{3}$. De hecho, como el interesante diario de Manuel Luengo nos confirma, ya desde el inicio de esta difícil cohabitación emergieron unas diferencias culturales entre los jesuitas españoles y los italianos (sobre todo los que pertenecían a la Provincia véneta): también después de la supresión canónica, las relaciones entre los ex jesuitas de los dos grupos fueron a menudo tensas, y así lo ratifican las polémicas literarias del tiempo ${ }^{4}$.

El papel de los jesuitas italianos en el otoño de 1768 se redujo a proporcionar informaciones prácticas sobre el destino final del viaje a los pequeños grupos que llegaban a la frontera del Estado pontificio, así como a contratar los alquileres -a menudo a favor de los particulares italianos- de los edificios donde iban a residir las once Provincias españolas. Esta tarea logística fue desarrollada fundamentalmente por las autoridades civiles del Estado de la Iglesia, o sea por los legados, sus vices y los gobernadores de las ciudades, siempre bajo el control de la Secretaría de Estado. Anteriormente, el mismo gobierno pontificio había marcado las líneas políticas: en primer lugar, los expulsos tenían que vivir sólo con el producto de la pensión vitalicia; en segundo lugar, se establecía que el destino final del exilio sería fundamentalmente las tres legaciones (Bolonia, Ferrara, Rávena) de la actual región de Emilia-Romagna; a cada Provincia se le asignaba una ciudad o unos pueblos para evitar una excesiva dispersión en el territorio; se prohibía a los expulsos españoles (exceptuando a los secularizados) pasar a Roma sin permiso de las autoridades civiles. Así, por ejemplo, los jesuitas castellanos tuvieron que residir en la ciudad de Bolonia y en los pueblos de su campiña; los aragoneses se establecieron en Ferrara; los mejicanos fueron divididos entre Bolonia y Ferrara; los toledanos se establecieron en Forlì, los chilenos en Imola y Rávena, los paraguayos en Faenza, etc.

La pensión vitalicia, que la Pragmática sanción del 2 de abril 1767 había otorgado a los sacerdotes (100 pesos sencillos) y a los coadjutores (90 pesos), fue el recurso fundamental que permitió a las nuevas comunidades jesuíticas reorganizarse en Italia: gracias a esta mísera renta, financiada por las ex temporalidades incautadas, la mayoría de los ignacianos españoles pudo sobrevivir durante las dos etapas del exilio italiano (1767-1798 y 1801-1815). Puede resultar algo paradójico que la estrategia de supervivencia fundamental, que permitió a la Asistencia española extrañada volver a definir su propia identidad y,

${ }^{3} \mathrm{~S}$. PAVone, Le astuzie dei gesuiti. Le false istruzioni segrete della Compagnia di Gesù e la polemica antigesuita dei secoli XVII e XVIII, Roma, 2000; ID., I gesuiti dalle origini alla soppressione, Roma-Bari, 2004; AA. VV., «Alle origini della Compagnia di Gesù», Rivista Storica Italiana, CXVII, 1, (2003) 5-178; P. Broggio, F. Cantù, P.-A. Fabre, A. Romano, I gesuiti ai tempi di Claudio Acquaviva. Strategie politiche, religiose e culturali tra Cinque e Seicento, Brescia, 2007.

${ }^{4}$ M. Luengo, Memorias de un exilio. Diario de la expulsión de los jesuitas de los dominios del Rey de España (1767-1768), Alicante, 2002.

Hispania Sacra, LXI

123, enero-junio 2009, 257-278, ISSN: 0018-215-X 
sobre todo, su estructura administrativa, se fundara en el «sueldo» público garantizado por el gobierno que la había expulsado. De hecho, ya desde la fase corsa del exilio, los superiores de las Provincias habían decidido juntar las pensiones particulares para formar un fondo común con que cubrir los gastos de cada comunidad; este método -que Madrid intentó prohibir desde el momento del embarque, si bien, al final, tuvo que aceptar- tenía la ventaja suplementaria de limitar el fenómeno de las secularizaciones, ya que permitía a los superiores un control más eficaz de sus propias comunidades. Así, frente a la falta de solidaridad exhibida por la rama italiana de la Orden, la administración comunitaria de los vitalicios permitió a los provinciales reorganizar, en los lugares del exilio, los colegios, las casas y los seminarios. Naturalmente, varias dificultades -fundamentalmente la falta de libros, los padres que habían muerto en el viaje, las secularizaciones, la oposición de los obispos y de los regulares italianos y los apuros financieros- impidieron que en Italia se reconstruyeran todas las estructuras originarias y obligaron a los superiores a juntar el cuerpo docente de los antiguos colegios y a inventar nuevas fórmulas organizativas ${ }^{5}$; en particular, reduciendo cuantitativamente las antiguas comunidades y fundando ex novo comunidades más pequeñas. Pero, a pesar de todo, la mayoría de las provincias, entre 1768 y 1773, logró alcanzar un buen nivel de eficiencia administrativa, también en el marco de la formación de aquellos escolares y novicios que habían decidido seguir a sus maestros en el exilio.

Precisamente, fue la habilidad demostrada por los superiores en reorganizar sus comunidades desde el exilio en Córcega el factor que convenció al Consejo Extraordinario a continuar la vigilancia desarrollada por los Comisarios; además, el pago de las pensiones obligó a Madrid a enviar a Italia a dos Comisarios Reales, Pedro La Forcada y Fernando Coronel, y al Comisario de Guerra, Luigi Gnecco (su padre, Gerónimo, pidió la jubilación después de la expulsión de los jesuitas de Córcega). El hecho de que Carlos III confiara el control de los expulsos en el territorio del Estado de la Iglesia a una burocracia ad hoc demuestra la voluntad del grupo de ministros responsable del exilio de la Asistencia española de mantener una «relación» con los religiosos extrañados: se trataba, en realidad, de un control político a distancia. En efecto, los Comisarios fueron la longa manus del Consejo Extraordinario en Italia, aunque, después de la extinción, estos funcionarios (particularmente, Luigi Gnecco y su sucesor Giuseppe Capelletti), al vivir en contacto con los expulsos durante más de treinta años, acabaron solidarizándose con ellos. En el caso particular del embajador español en Génova, Juan Cornejo, más que de solidaridad humana se trató de un apoyo

\footnotetext{
${ }^{5}$ Fue el caso de la Academia fundada por los jesuitas mejicanos en Bolonia, utilizada como instrumento pedagógico suplementario: véase C. E. RonAn, Francisco Javier Clavigero, S. J. (1731-1787), figure of the Mexican Enlightenment: his life and works, Roma, 1977.
} 
sistemático, ya que el ministro, muy próximo a la Compañía, protegió y respaldó de muchas maneras a los expulsos que decidieron residir en la capital de la República.

La extinción canónica de 1773 a través del breve Dominus ac Redemptor interrumpió este proceso de reconstrucción identitaria de la Asistencia española, ya que cada Provincia tuvo que disolver sus comunidades 6 . Instrucciones particulares promulgadas por el Consejo Extraordinario prohibieron a los ex jesuitas residir en uniones de más de tres; éstos, además, tenían que ser del mismo grado (con el fin de borrar el recuerdo de la vieja jerarquía). De hecho, muchas de las normas dictadas por Roma y Madrid en relación con la dispersión de las comunidades reconstruidas en Italia no se cumplieron, debido a las dificultades económicas de los religiosos: sin poder contar con la solidaridad de las comunidades disueltas, los ex jesuitas no podían sobrevivir únicamente con el dinero del vitalicio y con las ayudas que empezaron a llegar muy pronto de sus familiares. En efecto, al final de los años setenta, hubo una caída del poder adquisitivo del vitalicio público como consecuencia de una tendencia inflacionista general que, en el Estado de la Iglesia, se agravó por las reformas monetarias del Tesorero Fabrizio Ruffo: esta coyuntura afectó a los expulsos que no habían podido integrar su mísera renta. El gobierno, buen conocedor de esta situación gracias a los relatos de los Comisarios y a los informes de los propios ex jesuitas, toleró comunidades o congregaciones de diez miembros que, compartiendo los gastos del alquiler y de la comida, garantizaran un nivel de vida casi decente $^{7}$. Además, el progresivo envejecimiento de los ex jesuitas obligó a Madrid a conceder que los coadjutores vivieran junto a los sacerdotes para que así pudieran atenderles; de esta manera, los ex procuradores provinciales, es decir, los ecónomos, siguieron desarrollando su labor burocrática, fundamental también después de la extinción, porque ellos eran los encargados de cobrar el dinero de los Comisarios y de distribuirlo entre las diferentes casas.

Por otra parte, la supresión canónica, vivida por muchos ex jesuitas como una verdadera liberación, tuvo también efectos positivos. En primer lugar, les permitió abandonar el Estado de la Iglesia y residir en otros estados italianos, aunque seguía vigente la prohibición de vivir en los estados donde reinaban los Borbones: no sólo en el Reino de Nápoles, sino también en el Granducado de Toscana, cuya soberana era María Luisa de Borbón. Así, a partir del verano de 1773, muchos expulsos decidieron cambiar de residencia buscando fortuna en el centro y del norte de Italia, sobre todo, en Lombardía y en las repúblicas de

\footnotetext{
${ }^{6}$ M. Batllori, «La Compañía de Jesús en la época de la extinción», Archivum Historicum Societatis Iesu, XXXVII (1968) 201-231.

7 Hecho, éste, confirmado en septiembre de 1786 por Clemente Campos, secretario personal del conde de Aranda: véase OlaEcheA, En torno al ex-jesuita, pp. 231-232. 
Génova y de Venecia. Por ejemplo, Juan Andrés decidió en 1774 abandonar Ferrara, donde continuó residiendo su ex Provincia, la aragonesa, para vivir en Mantua. Se podría establecer una conexión entre esa «libertad» y una postura intelectual abierta a las Luces, porque es evidente que la falta de control practicado por los superiores permitió a muchos ex jesuitas (también a los secularizados, como Pedro Montengón) experimentar nuevas fórmulas culturales. Pero creo que sería peligroso generalizar esta interpretación a todos los miembros de la Asistencia española extrañada, ya que hay casos de secularizados que siguieron defendiendo la memoria de la Compañía, como también casos de expulsos (por ejemplo Vicente Requeno), que supieron conciliar su fidelidad al espíritu de la Orden ignaciana con una curiosidad hacia la cultura ilustrada.

De todas formas, la mayoría de los ex jesuitas españoles prefirió quedarse, hasta la llegada de los franceses en 1796, en la ciudades que les había atribuido el gobierno pontificio en 1768. Las razones fueron diversas. En primer lugar, muchos religiosos, considerándose siempre miembros de su ex Orden, entendían que el contacto con los otros hermanos garantizaría la supervivencia de la antigua identidad provincial; en segundo lugar, las dificultades económicas mencionadas obligaron o, por lo menos, aconsejaron a los jesuitas mantener una forma de solidaridad y de unión; y, por último, no todos los ex jesuitas tuvieron capacidad de iniciativa personal y prefirieron no cortar las relaciones que, a pesar de todo, habían conseguido establecer en los lugares del exilio, particularmente con las familias del patriciado y de la nobleza de la Emilia-Romagna ${ }^{8}$. Así, la movilidad de los expulsos estuvo estrechamente conectada con las oportunidades de trabajo que algunos de ellos supieron encontrar tanto fuera como en el interior del Estado de la Iglesia.

Desde esta perspectiva, el marco global de la progresiva integración de los ignacianos españoles en la estructura socioeconómica de la Italia del centronorte, particularmente en las instituciones docentes y culturales, representa actualmente uno de los temas de investigación de mayor interés. En efecto, los ex jesuitas españoles fueron muy hábiles en introducirse, gracias a su talento, en el sistema pedagógico del Estado de la Iglesia. No es casual que el primer ámbito en que, después de la extinción, los expulsos pudieron distinguirse fuera la educación privada. Muchos, incluidos los grandes nombres de la Asistencia, como Juan Andrés, actuaron como preceptores privados de los jóvenes cadetes de las familias nobles o patricias de la Emilia-Romagna: habitualmente estos ex jesuitas «ayos» vivían en el mismo palacio de la familia y compartían la existencia cotidiana con sus protectores. No siempre este tipo de vida resultaba plenamen-

\footnotetext{
${ }^{8}$ Véanse las preciosas informaciones proporcionadas por dos ilustres viajeros españoles de la época: L. Fernández de Moratín, Viage a Italia, ed. B. Tejerina, Madrid, 1988; N. Rodríguez Laso, «Diario en el viage de Francia e Italia (1788)», ed. A. Astorgano ABAJo, Zaragoza, 2006.
} 
te satisfactorio. A veces, como en el caso del valenciano Antonio Conca, se consideraban explotados; otros, como Lorenzo Hervás y el andaluz José Fernando Silva, se vieron involucrados en las agrias disputas propias de las familias nobiliarias de la Europa de Antiguo Régimen. De todas formas, es importante subrayar que las capacidades educativas de los expulsos fueron solicitadas por las élites italianas de la época: lo que hacía más atractivo contratar a un preceptor jesuita, y además extranjero, era el «saber tradicional», fundamentalmente humanístico, que sabían trasmitir a sus discípulos.

De hecho, los expulsos lograron introducirse en el cuerpo docente y, después de la extinción, también en las estructuras educativas inferiores, superiores y universitarias de la Italia del centro y del norte, empezando por las Universidades de Bolonia ${ }^{9}$ y Ferrara ${ }^{10}$; conocemos, además, casos de expulsos promovidos por las autoridades pontificias para dirigir seminarios, colegios u orfanatos ${ }^{11}$.

Naturalmente los expulsos se dedicaron también a las tareas religiosas, a las que se entregaban antes de la expulsión: efectivamente, otro ámbito «ocupacional» en el cual los expulsos sobresalieron fue la Iglesia. Es conocido el caso de aquellos jesuitas que trabajaron en las cárceles boloñesas como confesores, mientras en los años ochenta varios obispos nombraron a otros jesuitas españoles párrocos y auxiliares de las parroquias más pobres del Estado de la Iglesia. Naturalmente, en este sector el «mercado», si así se puede calificar, del lugar del exilio (el Estado de la Iglesia) estaba saturado, pues la oferta superaba con creces la demanda de eclesiásticos; no es casual que el cardenal Torrigiani calificara de «ociosos» a los jesuitas españoles. Estaba claro que las estructuras eclesiásticas pontificias no podían integrar a todos los sacerdotes o coadjutores espirituales de la Asistencia española, sobre todo después de la llegada a Roma de los cofrades portugueses y franceses. De todas formas, jesuitas como Hervás o el mejicano José Lino Fábrega Bustamante, protegido por el cardenal Borgia, consiguieron ponerse bajo la protección de los obispos y cardenales trabajando como secretarios o bibliotecarios. Fue una minoría, aunque sus casos demuestran que podían alcanzar hasta los cargos más altos de la sociedad pontificia.

Entre las actividades que, a medio camino entre la labor intelectual y la actividad de gestión, vieron una activa e importante participación de los ex jesuitas españoles, destaca, sin duda, la de bibliotecario: muchos expulsos consiguieron trabajar como directores, vicedirectores o simples funcionarios en algunas de las bibliotecas italianas más prestigiosas de la época. Son bien conocidas las

\footnotetext{
${ }^{9}$ En Bolonia sobresalieron el filipino Manuel Rodríguez Aponte, profesor de griego de 1794 hasta 1798; el aragonés Joaquín Pla, catedrático de caldeo en 1794.

${ }^{10}$ Como el catalán Antonio Vila, profesor de letras clásicas en Comacchio.

${ }^{11}$ El aragonés Sebastián Soldevilla, por ejemplo, fue director de 1779 hasta 1804 del Pio Istituto degli esposti de Ferrara.

Hispania Sacra, LXI

123, enero-junio 2009, 257-278, ISSN: 0018-215-X
} 
experiencias del valenciano Luciano Gallissà, director durante muchos años (1782-1798) de la Biblioteca Pública de Ferrara, o de su ex hermano Juan Andrés, responsable de la Biblioteca Real de Nápoles durante los primeros años del siglo XIX (1805-1814).

Este interés por la administración de la bibliotecas se explica por la actitud que la Compañía había desarrollado hacia la biblioteconomía y, en general, la organización del saber, y también por el hecho de que, en el siglo XVIII, las bibliotecas se habían transformado en uno de los lugares privilegiados de la sociabilité de las élites. En toda Europa, uno de los rasgos más peculiares de la labor intelectual promovida por los jesuitas, antes y después de la extinción canónica, fue el intento de integrarse y, a veces, apoderarse, de todos los medios de la sociabilidad cultural, particularmente, las academias, las tertulias, las logias masónicas, las tipografías o las redacciones de los periódicos ${ }^{12}$. Como demuestran los últimos estudios dedicados a la Compañía en el siglo XVIII, este afán no provenía sólo de la voluntad de promoción social, sino de una específica estrategia cultural e ideológica muy bien diseñada: los jesuitas intentaron confrontarse y enfrentarse en su propio terreno con los intelectuales ilustrados de toda Europa. Dicha estrategia fue desarrollada por los propios expulsos, ya que ellos fueron muy hábiles para integrarse en todos los centros italianos de la sociabilité: casi todas las grandes figuras intelectuales de la ex Asistencia española asistieron a tertulias, colaboraron con los principales periódicos literarios y políticos italianos, trabajaron y dirigieron tipografías o se asociaron a academias. Queda sólo una duda respecto a su afiliación a la Masonería local, ya que no ha sido todavía demostrada una sistemática voluntad de introducirse en las logias italianas ${ }^{13}$.

Muchos ejemplos se pueden alegar. Citaré únicamente los casos bien conocidos de Juan Andrés, protagonista de las actividades culturales de la Accademia delle scienze, lettere ed arti de Mantua; del andaluz Juan de Osuna, quien dirigió en los años ochenta la tipografía Biasini de Cesena y fundó dos periódi$\cos ^{14}$; o los de Conca, Arteaga, Masdeu o Llampillas, que colaboraron con numerosos periódicos en Florencia, Roma y Bolonia. La lista se podría ampliar fácilmente.

Para terminar esta panorámica, hay que recordar que no todos los ex jesuitas cultivaban ambiciones literarias o se dedicaban a tareas culturales. Antes bien,

12 A. Trampus, I gesuiti e l'Illuminismo. Politica e religione in Austria e nell'Europa centrale (1773-1798), Firenze, 2000.

${ }^{13}$ G. Giarrizzo, Massoneria e illuminismo nell'Europa del Settecento, Venezia, 1994.

${ }^{14}$ Las «Notizie politiche» (1788-1795) y las «Notizie letterarie» (1791-1792). Véase G. CALABRÒ, «Tradizione culturale gesuitica e riformismo illuministico. Juan de Osuna e le 'Notizie Letterarie' (1791-1792)», en AA. VV., Saggi e ricerche sul Settecento, Napoli, 1968, pp. 513-574. 
la mayoría, particularmente de los coadjutores, había sido formada en la misma Compañía para ocuparse de actividades prácticas y manuales; así que ellos (como los secularizados que habían perdido la solidaridad de sus ex hermanos) tuvieron que añadir otra renta al vitalicio público, buscando trabajo en el ámbito de las artes liberales y manuales. Muchos expulsos se dedicaron a la medicina, y no faltaron los que trabajaron como operarios, albañiles o comerciantes. Desde finales de los años ochenta era muy seria la situación económica de los jesuitas secularizados antes de la extinción canónica, porque normalmente se habían casado y habían formado familias amplias, a veces hasta con ocho hijos. En los años noventa, estos ex jesuitas pidieron masivamente al Consejo Extraordinario y a la Secretaría de Estado ayudas económicas suplementarias porque el vitalicio, ya muy devaluado, no les permitía mantener a sus familias. Naturalmente aquellos jesuitas que, por su vejez o enfermedad, no podían trabajar y no podían ser asistidos por sus ex cofrades, tuvieron que ser internados en los hospitales locales.

En resumen, querría destacar que el análisis de las colocaciones laborales de los expulsos sería un magnífico tema de investigación para los historiadores de la economía y de la sociedad italianas del Antiguo Régimen.

LAS ESTRATEGIAS CULTURALES DE LOS EXPULSOS Y SUS ACTITUDES HACIA LA ILUSTRACIÓN EUROPEA

La inmensa producción manuscrita e impresa de los ex jesuitas españoles ${ }^{15}$, junto a la identidad plural de la numerosa Asistencia española, con casi cinco mil religiosos distribuidos en once Provincias, no permite reducir a una sola fórmula interpretativa fenómenos a menudo distintos. En mi investigación he analizado las actividades culturales de los expulsos en relación con los contextos españoles e italianos (concretamente el del Granducado de Toscana), los contactos epistolares muy amistosos entre los hermanos Andrés y los intelectuales aragoneses y valencianos (como Juan Antonio Mayans, Manuel Sisternes y Feliu o Juan Sempere y Guarinos). He intentado mostrar la habilidad e inteligencia con las cuales los expulsos supieron dialogar con las élites intelectuales y políticas de las dos penínsulas, más allá de las polémicas sobre su ex Orden ${ }^{16}$.

El análisis de las distintas sensibilidades culturales preexistentes a la expulsión y las que produjo el mismo exilio constituye un prisma muy útil para com-

\footnotetext{
15 Véase L. Hervás y PANDuro, Biblioteca jesuítico-española (1759-1799), ed. A. Astorgano ABAJO, Madrid, 2007.

16 N. GUASTI, L'esilio italiano dei gesuiti spagnoli. Identità, controllo sociale e pratiche culturali (1767-1798), Roma, 2006.

Hispania Sacra, LXI

123, enero-junio 2009, 257-278, ISSN: 0018-215-X
} 
prender mejor las muchas «almas» del Catolicismo del Setecientos y la misma Ilustración. «Leer» las Luces europeas y el reformismo inspirado en ellas con los ojos de los ignacianos es interesante desde muchas perspectivas. Primero, nos permite fijar cómo se percibió el fenómeno en un sector relevante de la sociedad y de la cultura del siglo XVIII, el de los religiosos regulares que constituía una parte importante de los «intelectuales» y del cuerpo docente en los países católicos; y después nos permite medir las distintas reacciones producidas por el encuentro o la colisión entre la Ilustración -o, si se prefiere, las Ilustraciones- y las numerosas facetas del Catolicismo de los jesuitas.

Por estas razones, es posible decir que también en la Asistencia española, como ocurre en otros grupos «nacionales» de la Orden ${ }^{17}$, particularmente después de la expulsión, aparecen dos tendencias o dos «almas». Una siguió considerándose fiel a la tradición contrarreformista, rehusando la contaminación con la «filosofía moderna»-se tratara del «ateo-materialista» Spinoza, del «mecanicista» Descartes, del empirismo de Locke y de la física de Newton- empeñándose en defender a la Santa Sede, al Papa y a la extinguida Compañía a través de libelos polémicos. Es evidente que este sector conservador de la Orden, aún después de su extinción, siguió combatiendo explícitamente a los philosophes y las reformas regalistas, ya que se reputaba heredero de la tradición de la Escolástica y del catolicismo militante de la Contrarreforma, y consideraba sospechoso conciliar razón y fe. Personajes como Manuel Luengo, a pesar de la supresión, seguían considerándose idealmente miembros de la Orden, cuya misión era la defensa de la autoridad espiritual y del poder temporal de la Santa Sede ${ }^{18}$.

En cambio, otro grupo de expulsos intentó desarrollar un diálogo con las élites reformadoras italianas y españolas, procurando reconducir la cultura ilustrada en el marco del Catolicismo. Para limitar los efectos «radicales» de la Ilustración, varios intentaron pactar con los círculos reformadores e ilustrados, adoptando su lenguaje y sus medios de divulgación, e introduciéndose en los centros de la sociabilité del Setecientos. Se trató de una estrategia alternativa, fundada en el eclecticismo y en el sincretismo, a la promovida por los hermanos todavía arraigados en la cultura del siglo anterior, porque tenían el mismo objetivo final: salvar la Iglesia y la Santa Sede de los peligros de una generalizada deslegitimación ${ }^{19}$. En ambos casos el especialista del siglo XVIII puede

17 P. Bianchini (ed.), Morte e resurrezione di un Ordine religioso. Le strategie culturali ed educative della Compagnia di Gesù durante la soppressione (1759-1814), Milano, 2006.

18 E. GimÉnEz LóPEZ, «La apología del jesuitismo: el P. Isla en Italia»; M. L. LóPEz MuÑOz, «Una arma de los jesuitas españoles expulsos: la sátira política», en A. MESTRE SANCHÍs y E. GIMÉNEZ LóPEZ (eds), Disidencias y exilios en la España Moderna, Alicante, 1997, pp. 573-607; 703-718.

19 De hecho esta técnica cultural sincrética, en la segunda mitad del siglo XVIII, fue también uno de los medios utilizados por los ignacianos para redefinir su propia identidad: una identidad que las expulsiones y la supresión canónica intentaron borrar, sin conseguirlo. Así, en las primeras dos décadas 
utilizar las impugnaciones y las re-elaboraciones de los mensajes claves de la Ilustración para comprender cómo la «opinión pública» europea percibía los cambios culturales, políticos y de mentalidad producidos por las Luces.

La historiografía suele definir a los expulsos eclécticos y abiertos como «ilustrados» (o «reformadores», términos utilizados a veces en función de sinónimos), sin detenerse, muchas veces, en definir las características de esta Ilustración jesuítica. En cambio, esos términos historiográficos se deben utilizar con exactitud semántica porque pueden provocar confusión y malentendidos, sobre todo fuera de España: no es sólo una cuestión terminológica, sino también un problema de definición conceptual. En el caso de los ex jesuitas, sería útil usar diversas etiquetas que los especialistas europeos del Setecientos utilizan desde hace mucho tiempo.

Así, podemos considerar ese grupo de expulsos abiertos a la Nueva Ciencia y a la filosofía moderna miembros de aquel «moderate main-stream» de la Ilustración europea que combatió a la Ilustración radical, batalla bien estudiada por Jonathan Israel en sus dos últimos libros ${ }^{20}$. Igualmente, puede servir el concepto de Ilustración católica o de Aufklärung católica ${ }^{21}$, aunque muchos especialistas de la Ilustración, como Vincenzo Ferrone, han rechazado la asociación entre el sustantivo y el adjetivo ${ }^{22}$. Más ambigua es la costumbre, muy frecuente en el caso de los estudios dedicados a los jesuitas mejicanos y aragoneses, de utilizar la definición de «humanista» como si fuera sinónimo de «ilustrado»: la afición a los autores griegos y romanos, rasgo típico de la cultura y de la pedagogía jesuítica desde el siglo XVI, no siempre condujo a una actitud abierta hacia la modernidad y sus desafíos.

Después de haber definido el término, hay que aplicarlo con exactitud para que no pierda su sentido historiográfico. Para los jesuitas españoles, creo que «ilustrados» fueron efectivamente aquellos que, como Juan Andrés, Vicente Requeno, Juan Francisco Masdeu, Antonio Conca, Lorenzo Hervás o Pedro Mon-

del siglo XIX, la antigua alma militante consiguió englobar sin excesivos traumas a los hermanos que habían dialogado con las Luces y los grupos reformadores. Esta «revolución copernicana» se puede detectar también en el trayecto intelectual de varios ignacianos.

20 J. I. ISRAEL, Radical Enlightenment. Philosophy and the making of Modernity (1650-1750), Oxford, 2001; ID., Enlightenment contested. Philosophy, Modernity, and the emancipation of man (16701752), Oxford, 2006.

${ }^{21}$ M. Rosa, Riformatori e ribelli nel '700 religioso italiano, Bari, 1969; ID., Politica e religione nel '700 europeo, Firenze, 1974; ID., Settecento religioso. Politica della Ragione e religione del cuore, Venezia, 1999; A. Mestre SANChís, La actitud religiosa de los católicos ilustrados, en A. Guimerá (ed.), El reformismo borbónico: una visión interdisciplinar, Madrid, 1996, pp. 147-163.

22 V. Ferrone, «Chiesa Cattolica e Modernità», en F. Bolgiani, V. Ferrone, F. Margiotta BroGLIO (eds), Chiesa cattolica e modernità. Atti del convegno della Fondazione Michele Pellegrino, Bologna, 2004, pp. 17-131.

Hispania Sacra, LXI

123, enero-junio 2009, 257-278, ISSN: 0018-215-X 
tengón, intentaron dialogar con las Luces: esta etiqueta puede definir aquel grupo de jesuitas eclécticos o sincréticos que intentaron manejar, gracias a su talento e inteligencia, la moda neoclásica, unas teorías o unos conceptos de la nueva cultura enciclopédica y científica, apoderándose de los lugares de la sociabilité ilustrada y utilizando sus medios de comunicación y debate. Este grupo consiguió dialogar también con los ilustrados y reformadores españoles: no es casual que en los años ochenta Floridablanca los considerara útiles para su campaña de prensa en defensa de la nación española. Hay que subrayar que los ex jesuitas no fueron los únicos intelectuales pertenecientes a las órdenes regulares que adoptaron esta postura ecléctica: en toda la Europa Católica del Setecientos varios oratorianos y hasta algunos barnabitas (como el italiano Giacinto Sigismondo Gerdil) compartieron esta apertura al diálogo con la ciencia moderna y las corrientes moderadas de la Ilustración ${ }^{23}$. Sin duda, los jesuitas sobresalieron, siendo verdaderos maestros de eclecticismo filosófico: uno de los mejores científicos newtonianos de la Italia del siglo XVIII fue el jesuita Ruggero Giuseppe Boscovich ${ }^{24}$.

De todas formas, no sería correcto presentar esta postura ecléctica, abierta a la filosofía, la ciencia y la cultura ilustrada, como el efecto de una estrategia oportunista o instrumental. El «sincretismo ignaciano» nacía de una antigua tradición cultural que había producido el éxito y la penetración de la Compañía en Europa y en todo el Mundo ${ }^{25}$. En otros términos, los jesuitas desarrollaron en el Setecientos la estrategia que, a lo largo del siglo anterior, se proponía conciliar el tomismo con las rupturas epistemológicas propuestas por el pensamiento de Descartes, Galilei, Spinoza, Gassendi, Leibniz, Wolff, Locke y Newton. Los últimos estudios dedicados a la tradición científica promovida en los siglos XVI y XVIII por las élites culturales de la Compañía, como los de Antonella Romano sobre la matemática ${ }^{26}$, han demostrado que también los jesuitas contribuyeron con sus obras y su labor docente a la «revolución científica» y, en una palabra, a la modernidad 27 .

${ }^{23}$ C. Borghero, «Gerdil e i moderni: le stratgie apologetiche di un anti-illuminista», en AA. VV., Nuove ragioni dell'anti-illuminismo in Francia e in Italia, Pisa - Genève, 2001, pp. 31-61.

${ }^{24}$ GUASTI, L'esilio italiano, pp. 263-264 (y bibliografía aquí citada).

${ }^{25}$ Los últimos estudios dedicados a la labor misionera definen este rasgo peculiar de la estrategia cultural de la Compañía «cultural intermediacy». Véase D. RAmAda CuRTO, «The jesuits and Cultural Intermediacy in the Early Modern World», Archivum Historicum Societatis Iesu, LXXV, 147 (2005) 3 22. Véase también J.-P. RUBIÉs, «The concept of cultural dialogue and the jesuit method of accomodation: between idolatry and civilization», Ibidem, pp. 237-280.

${ }^{26}$ A. Romano, La contre-réforme mathématique. Constitution et diffusion d'une culture mathématique jésuite à la Renaissance (1540-1640), Roma, 1999; ID., «Les jésuites entre apostolat missionnaire et activité scientifique (XVIe-XVIIIe siècles)», Archivum Historicum Societatis Iesu, LXXV, 147 (2005) 213-236.

${ }^{27}$ P.-A. FABre y A. Romano (eds), «Les jésuites dans le monde moderne. Nouvelles approches historiographiques», Revue de Synthèse, IV, 2-3 (1999); AA. VV., «Anatomia di un corpo religioso. L'identità dei gesuiti in Età Moderna», Annali di storia dell'esegesi, XIX, 2 (2002). 
La «mediación cultural» entre España e Italia fue la principal razón del éxito literario de los expulsos ${ }^{28}$. La necesidad de moverse entre dos contextos -0 , más bién, entre los múltiples contextos, si se consideran las muchas facetas culturales y políticas de la monarquía hispánica y de la Italia del Setecientos- condujo a muchos de ellos a calibrar sus proyectos editoriales y culturales en función del destinatario. Los expulsos consiguieron, entonces, adaptar temas, ideas y conceptos a lectores distintos, desde Floridablanca a la Sociedad Aragonesa de Amigos del País ${ }^{29}$, desde las élites toscanas a los prelados romanos o a los legados de la Emilia-Romagna ${ }^{30}$. Bajo esta perspectiva el análisis sistemático, que todavía falta, de las dobles versiones de sus obras, en lengua castellana o en italiano, ofrece una pista de investigación de gran interés, porque no cabe duda de que los autores, en sus traducciones, adaptaron sus textos al nuevo destinatario.

La aragonesa y la mejicana ${ }^{31}$, en su conjunto, fueron las más dinámicas de las once Provincias de la ex Asistencia española. La primera se distinguió por su capacidad para participar en los principales debates italianos y europeos. En esto tuvo su parte la buena calidad de la instrucción clásica de los colegios y las casas de donde procedían los padres, como han demostrado Batllori, Casanovas y Mestre ${ }^{32}$; pero, en Italia, el éxito literario de personajes como Juan Andrés, Antonio Conca, Juan Francisco Masdeu, Francisco Xavier Llampillas o Juan Nuix se debió también a una razón lingüística, o sea su capacidad de aprender el italiano debida al bilingüismo. El catalán Llampillas, según el embajador español de Génova Cornejo, después de vivir diez años en Italia, escribía mejor el italiano que el castellano ${ }^{33}$.

El cambio político que se produjo en 1776 influyó mucho en el desarrollo de las publicaciones de los expulsos. A pesar de haber sido el protagonista de las gestiones diplomáticas que condujeron a la supresión de la Orden ${ }^{34}$, el conde de

${ }^{28}$ M. TIETZ (ed.), Los jesuitas españoles expulsos. Su imagen y su contribución al saber sobre el mundo hispánico en la Europa del siglo XVIII, Madrid-Frankfurt am Main, 2001.

29 A. Astorgano Abajo, «El abate Vicente Requeno y Vives (1743-1811) en la Real Sociedad Económica Aragonesa (1798-1801)», Rolde, 85-86 (1998) 56-73; V. REQUENO Y VIVES, Escritos filosóficos, ed. A. Astorgano Abajo, Zaragoza, 2008.

${ }^{30}$ P. BellettinI, «Tipografi romagnoli ed ex gesuiti spagnoli negli ultimi decenni del Settecento», en L. BALDACChin y A. MANFron (eds), Il libro in Romagna. Produzione, commercio e consumo dalla fine del secolo XV all'età contemporanea, Firenze, 1998, vol. 2, pp. 557-657.

${ }^{31}$ E. M. St. Clair Segurado, Expulsión y exilio de la Provincia jesuita mexicana (1767-1820), Alicante, 2005; J. KLAIBER, Los jesuitas en América latina, 1549-2000, Lima, 2007.

32 BATLlori, La cultura; I. CASANOVAS, Documents per la història cultural de Catalunya en el segle XVIII, Barcelona, 1932-1934; A. Mestre Sanchís, Humanistas, políticos e ilustrados, Alicante, 2002.

33 GUASTI, L'esilio italiano, p. 419, nota 103.

${ }^{34}$ E. PACHeCo y De LeYva, «La intervención de Floridablanca en la redacción del Breve para la supresión de los jesuitas (1772-1773)», Escuela española de arqueología e historia en Roma, Cuadernos de trabajos, III (1915) 37-198; R. OlAECHEA, Las relaciones hispano-romanas en la segunda mitad del 
Floridablanca, después de ser nombrado Secretario de Estado, estrenó una nueva estrategia hacia los ex jesuitas, ya que promovió una tácita reconciliación entre el gobierno reformador y los expulsos. La ocasión llegó después de 17771778 y coincidió fundamentalmente con dos hechos relacionados entre sí, uno político y otro cultural: la Guerra de Independencia americana y la campaña de los filósofos franceses, escoceses e italianos contra la conquista de América realizada por la Corona española. A pesar de que la monarquía española terminó por admitir la rebeldía de las trece colonías contra Gran Bretaña (y, del año 1779, participando en la guerra), la gran actualidad durante aquellos años del tema de América transformó el generalizado interés americanista en un argumento polémico: sobre todo porque, como demostró la Histoire philosophique et politique des établissements et du commerce des Européens dans les deux Indes de Raynal y Diderot, se utilizó para condenar la colonización europea, causa de la destrucción material y cultural de las comunidades indias. Así, la imagen negativa que desde el siglo XVI rodeaba a la monarquía española -la llamada «leyenda negra» 35 - fue revitalizada y enriquecida por los philosophes franceses, los ilustrados escoceses y los literatos italianos. Los tres elementos básicos de dicho paradigma fueron, como se sabe, los efectos (humanos y económicos) negativos de la conquista de América ${ }^{36}$, el papel desarrollado por la Inquisición en el retraso científico ibérico y el influjo corruptor del Barroco en la literatura europea y en el buon gusto italiano. De ellos, el tema americanista adquirió una importancia polémica desconocida antes de la Revolución de las trece colonias inglesas.

Desde la segunda mitad de los años setenta, Floridablanca y otros ministros, particularmente el Secretario del Consejo de Indias José de Gálvez, empezaron a premiar con pensiones dobles a todos los expulsos que escribieran obras y confutaciones contra los textos de Raynal, Robertson, Marmontel y otros escritores (como Nicolas Masson de Morvilliers, autor en 1783 de la voz Espagne en la sección geográfica de la Encyclopédie Méthodique) que condenaban la Conquista y la conversión de los indios, y además contra los naturalistas ilustrados, como Buffon y de Pauw, que despreciaban la flora y la fauna del nuevo mundo. Se trató de una verdadera estrategia de propaganda, y los jesuitas no

siglo XVIII, Zaragoza, 1999 (1 ${ }^{\text {a }}$ ed. Zaragoza, 1965), pp. 308-312 y 363-382; I. Pinedo y A. ZABALA, «Bernis y Floridablanca: dos diplómaticos de la Ilustración en la campaña de extinción de los jesuitas (1769-1773)», Estudios de Geografía e Historia-Universidad de Deusto, 18 (1988) 523-536; F. J. BELMONTE Mas, «José Moñino en Roma: el Breve de extinción de la Compañía de Jesús», en Mestre SANCHÍs y GiMÉNEZ LóPEZ (eds), Disidencias y exilios, pp. 739-746.

35 Entre los muchos estudios sobre este paradigma, véase la importante síntesis de R. GARCíA CÁRCEL, La leyenda negra. Historia y opinión, Madrid, 1992.

36 No es casual que la fuente histórica más explotada por los ilustrados europeos fuese la Relación de Bartolomé de Las Casas. 
fueron los únicos intelectuales en ser premiados con incentivos en dinero: todos los mejores escritores y polemistas españoles, empezando por Cadalso, Cavanilles, Forner, Muñoz, etc., cooperaron en la defensa del «honor nacional» contra las que fueron consideradas verdaderas calumnias de los extranjeros ${ }^{37}$.

Que se tratara de una auténtica estrategia lo prueban también otros hechos, como la congelación, pretendida por Gálvez (posiblemente convencido por Pérez Bayer), de la versión española de la History of America de Robertson, que Campomanes había encargado en 1777 al académico de la historia Ramón Guevara Vasconcelos o la sucesiva reelaboración hecha por el duque de Almodóvar de la Histoire de Raynal y Diderot ${ }^{38}$.

Muy pocos expulsos consiguieron alcanzar una tranquilidad económica y profesional: la mayoría seguía sobreviviendo gracias al vitalicio público, y este hecho fue hábilmente explotado por el gobierno de Carlos III. Así, la forma de administrar la pensión pública, afectada, como hemos visto, por una progresiva tendencia inflacionista, influyó en las actividades culturales y editoriales de los expulsos. Entre las centenares de peticiones que ellos enviaron a Madrid con la esperanza de recibir una ayuda económica suplementaria, las que subrayaban los «méritos literarios» conocieron un alza notable ya en los últimos años setenta. Está claro que en aquellos años la pensión se transformó, por voluntad del gabinete dirigido por Floridablanca, de un simple método de control disciplinar en algo nuevo: el gobierno español, como explicaron en sus cartas Floridablanca y Azara, hubiera premiado con ayudas de coste suplementarias a los religiosos que, como Llampillas, Masdeu, Requeno, Andrés, etc., se empeñaban en defender «el honor nacional» ofendido por los literatos extranjeros. El patriotismo, a veces exasperado, que aparece en las obras de muchos expulsos, más que un aspecto del naciente Romanticismo, fue muy a menudo un efecto de la campaña de propaganda promocionada desde Madrid. Además, el patriotismo demostrado por los expulsos no fue tan vulgar y elemental, tal y como algunos historiadores han sostenido. Sobre todo, hay que distinguir entre los muchos patriotismos desarrollados por ellos: el patriotismo jesuítico, que exaltaba la obra de conversión al Catolicismo de los indios que la Compañía había protago-

${ }^{37}$ F. LOPEZ, Juan Pablo Forner et la crise de la conscience espagnole au XVIIIe siècle, Bordeaux, 1976; E. GIMÉNEZ LóPEZ y J. PRADELls NADAL, «Correspondencia entre Aranda e Ignacio de Heredia con Manuel de Roda, durante la embajada en París (1773-1781)», en J. A. FerRer BenimeLi (dir.), El conde de Aranda y su tiempo, Zaragoza, 2000, vol. 2, pp. 285-299; A. Mestre SAnChís, Apología y crítica de España en el siglo XVIII, Madrid, 2003.

38 P. Rodríguez de CAmpomanes, Epistolario (1778-1802), ed. J. Herrera Navarro, Madrid, 2004, vol. 1, pp. 15-18, 21-23, 25-27, 39-40, 117; G. IMBRUGLIA, «Qualche nota sul conte di Campomanes», Rivista Storica Italiana, XCIV, 1 (1982) 204-229; J. LYNCH, Bourbon Spain, 1700-1808, Oxford, 1989, pp. 253-254; G. B. PAQUETTE, Enlightenment, Governance, and reform in Spain and its Empire (1759-1808), Houndmills - New York, 2008, pp. 45-55.

Hispania Sacra, LXI

123, enero-junio 2009, 257-278, ISSN: 0018-215-X 
nizado; el proto-patriotismo criollo de los expulsos americanos como Clavigero; el patriotismo castizo de los jesuitas conservadores que seguían pensando que la limpieza de sangre, el sentido del honor, la fidelidad al Papa y el escolasticismo constituían una mezcla indivisible; o, finalmente, el patriotismo muy moderado, de origen austracista y mayansiano, de Andrés.

Los ilustrados europeos no fueron los únicos blancos de la polémica patriótica y filo-hispana de los jesuitas expulsos: ellos criticaron también a los literatos y a los eruditos italianos que, aunque compartían la misma postura crítica, o bien moderada, hacia la Ilustración, creían que la dominación española hubiese perjudicado a la cultura italiana. Es el caso de los ex jesuitas italianos Saverio Bettinelli y Girolamo Tiraboschi y del literato Pietro Napoli Signorelli. Masdeu criticó en su Storia critica di Spagna... (2 voll., 1781 y 1787), las tesis esbozadas por Bettinelli en el Risorgimento d'Italia negli studi, nelle arti e ne' costumi dopo il mille (1775), así como la interpretación desarrollada por Napoli Signorelli en su Storia critica de' teatri antichi e moderni (1777): según ellos, los españoles, desde Marcial y Séneca hasta Calderón, habían contribuido a corromper el buen gusto literario italiano. Masdeu, naturalmente, se opuso a esta visión antiespañola, afirmando exactamente lo contrario. Las mismas críticas recibió la Storia della letteratura italiana (13 voll. 1772-1782) de Tiraboschi, en la que se argumentaba que el período de la dominación española -o sea la época del Barroco- coincidió con una generalizada decadencia de la cultura italiana. Esteban Arteaga, Tomás Serrano y Francisco Javier Llampillas, en sus ensayos y reseñas, criticaron duramente los prejuicios del ex jesuita italiano. Juan Andrés fue más prudente en sus textos, y no sólo por la profunda amistad que le unía a Tiraboschi: en primer lugar, su patriotismo, heredero de la tradición austracista y de la erudición de Gregorio Mayans, era más blando y complejo y eso le evitó colisionar con su amigo italiano; antes bien, criticó, en sus cartas privadas $^{39}$, la postura violenta y exageradamente nacionalista de las impugnaciones de sus ex cofrades, y por eso desarrolló una apología «indirecta» de España. En segundo lugar, su convicción filosófica e ideológica hacia la Ilustración, la ciencia moderna y la disuelta Compañía coincidían con las apoyadas por Tiraboschi: la aceptación de unos aspectos de la Ilustración y su actitud reformadora impedían que Andrés aceptara unos argumentos excesivamente patrióticos que, muchas veces, consistían sólo en una banal inversión de las tesis de sus adversarios.

De todas formas, dichos jesuitas fueron premiados con pensiones dobles porque habían cumplido con la campaña propagandística promocionada por el gobierno dirigido por Floridablanca.

39 J. ANDRÉs, Epistolario, ed. L. BRUNORI, Valencia, 2006, vol. 1, pp. 142-143, 147-155. 
Lo mismo podemos decir de los numerosos ex jesuitas de las Provincias sudamericanas que elaboraron historias sobre sus patrias locales o sobre las misiones en las que habían trabajado. Es bien conocido que el ministro de Indias Gálvez y su sucesor Antonio Porlier se informaron, a través del embajador español en Roma y de los Comisarios, de las obras que los jesuitas criollos o los que habían sido misioneros estaban escribiendo en el exilio. Este interés terminó, en los años ochenta, por alentar a muchos ex jesuitas a escribir y traducir al castellano obras apologéticas sobre América. Recordemos la Storia antica del Messico (4 voll., 1780-1781) y la Storia della California (2 voll., 1789) de Francisco Javier Clavigero; el Saggio di storia naturale e civile del Chili (2 voll., 1782-1787) de Juan Ignacio Molina; la Historia del Reino de Quito (sin imprimir hasta el 1841-1844) de Juan de Velasco; el Saggio sulla Storia Naturale della provincia del Gran Chaco (1789) de Josef Jolís; el Saggio di storia americana... (4 voll., 1780-1784) de Filippo Salvatore Gilj; o, por último, la Trasformazione dell'America... (1790) de Antonio Julián ${ }^{40}$.

Por ello, no es de extrañar que también los jesuitas metropolitanos, sin haber estado nunca en América, como Juan Nuix, escribieran obras polémicas en contra de los naturalistas ilustrados y de los historiadores que compartían los tópi$\cos$ de la nueva versión ilustrada de la «leyenda negra» 41 . Pero, en general, la generosidad gubernamental hacia los ex jesuitas criollos que escribían sobre asuntos americanos fue menos amplia y muchas de sus obras o no fueron premiadas con pensiones dobles, o no se imprimieron, como la de Juan Celedonio Arteta.

De todas formas, sería injusto e incorrecto afirmar que las obras de los expulsos premiadas por el gobierno de Madrid no tuvieran un influjo en la cultura italiana de su tiempo. Todo lo contrario, como demuestran los elogios de diversos ilustrados italianos: por ejemplo, los que Carlo Denina dirigió desde Berlín a Andrés y Osuna por sus críticas al artículo Espagne de la Encyclopédie Méthodique; o los que Gian Rinaldo Carli rindió a Clavigero en sus Lettere Americane (1781-1783). La capacidad de argumentar de los expulsos pareció muy eficaz también en Italia. Naturalmente no faltaron malentendidos con los interlocutores italianos, también con aquellos intelectuales moderados que compartían el mismo lenguaje político y cultural del sector más abierto de la ex Asistencia española. El ejemplo del fracaso de la colaboración entre el grupo de ignacianos valencianos liderado por Juan Andrés y los académicos florentinos,

\footnotetext{
${ }^{40}$ A. Gerbi, La disputa del Nuovo Mondo, Milano, 2000 (3a ed.); J. CAÑIZAREs-EsGUERra, How to write the history of the New World. Histories, Epistemologies, and Identities in the Eighteenth-Century Atlantic World, Stanford, 2001.

${ }^{41}$ Naturalmente la metodología, como también la postura ideológica, de los ex jesuitas criollos aparecen muy distintas de las esgrimidas por sus cofrades metropolitanos.

Hispania Sacra, LXI

123, enero-junio 2009, 257-278, ISSN: 0018-215-X
} 
que he analizado siguiendo una pista de Franco Venturi, prueba la dificultad y los límites de aquel diálogo entre los expulsos y los varios contextos italianos ${ }^{42}$.

Por otra parte, el análisis del encuentro, o, si se prefiere, de la pacificación, entre los manteístas y los ignacianos después de la fractura traumática representada por la expulsión, proporciona una ocasión para reflexionar sobre la fuerza y los caracteres del reformismo ilustrado español. Efectivamente, el recíproco acercamiento entre ignacianos y manteístas podría ser considerado un síntoma de la debilidad cualitativa, cuantitativa y teórica de la Ilustración ibérica, sobre todo, considerando que los jesuitas, junto a los intelectuales cercanos al poder, como Forner y Cavanilles, fueron utilizados para responder a los philosophes y a los ilustrados europeos que habían resucitado el paradigma de la «leyenda negra». No insistiríamos demasiado en este último punto, fundamentalmente porque no creemos en las tesis de aquellos historiadores, como Francisco SánchezBlanco, que llegan a minusvalorar la Ilustración y el reformismo del reinado da Carlos $\mathrm{III}^{43}$. En primer lugar, hay que observar que la propaganda fomentada por el gobierno español, por los manteístas que dirigían las instituciones culturales de la monarquía y por el conde de Aranda desde la embajada de España en París, no tenía el objetivo de rechazar la Ilustración en su conjunto, sino sólo aquellas obras que difamaban a España y, más concretamente, a la «nueva» España de Carlos III, como el pamphlet sobre el Banco de San Carlos del marqués de Mirabeau. La resurrección de los argumentos fundamentales de la «leyenda negra», concretamente los de la crueldad de la colonización americana, el excesivo poder de la Inquisición y la inevitable decadencia económica de la monarquía hispana, fue percebida en Madrid como un ataque injustificado no tanto a la identidad nacional, sino al mismo gobierno reformado. Lo demuestra de modo evidente la universal indignación que provocó el artículo Espagne publicado en la Encyclopédie Méthodique (1783). Quizás el gobierno español se excedió en su reacción, al igual que muchos apologistas españoles (como Forner) revindicando como positivos justo aquellos elementos de la identidad nacional criticados, confirmando así con sus textos los estereotipos condenados por los ilustrados europeos. Me refiero a la exaltación de la religión católica considerada sinónimo de civilización y fundamento de la nación y de la monarquía espa-

42 F. VENTURI, «Economisti e riformatori spagnoli e italiani del Settecento», Rivista Storica Italiana, LXXIV, 3 (1962) 532-561; ID., Settecento Riformatore, Torino, 1984, IV, 1, pp. 285-289 y 306-309; N. GuAstI, «Sisternes entre los Georgofili de Florencia», Mágina, 12 (2004) 105-118; ID., «Antonio Conca traduttore di Campomanes», in TIETZ (ed.), Los jesuitas españoles, pp. 359-377; N. GUASTI, «Claroscuros de la fortuna de Campomanes en la Italia de la Ilustración», en D. MATEOS DorADo (ed.), Campomanes, doscientos años después, Oviedo, 2003, pp. 691-707; GUASTI, L'esilio italiano, pp. 293-328.

${ }^{43}$ F. SÁncheZ-Blanco, El Absolutismo y las Luces en el reinado de Carlos III, Madrid, 2002; ID., La Ilustración goyesca. La cultura en España durante el reinado de Carlos IV (1788-1808), Madrid, 2007. 
ñolas. Pero esto no significa negar la existencia de una Ilustración ibérica. Sería mejor hablar de un desgraciado malentendido nacido de la voluntad de los philosophes de construir un paradigma negativo que les servía para combatir sus batallas culturales y definir mejor su papel político.

España tuvo la mala suerte de haber sido la primera potencia mundial europea, y así despertó una «vulgata» negativa cuyos lugares comunes habían sobrevivido en la cultura europea. Lo que más le molestaba al conde de Aranda y a los manteístas, como Campomanes, era justo el intento de presentar la monarquía borbónica de Carlos III casi idéntica a la de los Austrias: o sea, la voluntad de negar el desarrollo que la sociedad, la cultura, la economía, la mentalidad ibéricas y americanas habían tenido en el Setecientos. En este sentido, defender los progresos de la nueva España de Carlos III significaba para Floridablanca, Aranda, Campomanes y los intelectuales del partido manteísta defenderse a sí mismos y a sus reformas.

Además, los mismos manteístas, como Azara, que en los años anteriores se habían distinguido por sus sentimientos antijesuíticos percibieron la contradicción y el peligro de aquel cambio de actitud hacia los expulsos. De hecho, la utilización de las plumas de los ignacianos extrañados en los años ochenta, como estamos viendo, apareció siempre oportunista, instrumental y subordinada a la propaganda oficial de Madrid y de las Sociedades Económicas de Amigos del País. Por ejemplo, Gálvez congeló la edición de la traducción-impugnación a la Histoire des deux Indes del jesuita andaluz Antonio Torres para no «quemar» la reelaboración hecha por el duque de Almodóvar, posiblemente encargada por Floridablanca mismo ${ }^{44}$.

La pacificación, si puede definirse así, nació de una contingencia políticocultural específica y fue oportunista: no sólo muchos jesuitas no alcanzaron la anhelada pensión doble por méritos literarios, sino que la «generosidad» gubernamental premió unas disciplinas, especialmente la historia de las provincias americanas y las «inofensivas» polémicas literarias, en palabras de Azara, y descuidó sistemáticamente a los sectores de la cultura española reformados por los manteístas después de la expulsión, como las antigüedades greco-romanas, la teología y las ciencias naturales. En este sentido, Inmaculada Fernández Arrillaga ha hablado de la pensión doble como «acicate», porque es evidente que la corte de Madrid premiaba a los que estaban realizando una buena labor en defensa de España ${ }^{45}$. Además, a los jesuitas que escribían historias nacionales (como Masdeu) se les negaba subrayar el papel de la Compañía en el desarrollo de la Monarquía, especialmente en América, y se les pedía la aceptación de la

\footnotetext{
44 GuAsti, L'esilio italiano, pp. 439-440.

45 I. Fernández Arrillaga, El destierro de los jesuitas castellanos (1767-1815), Salamanca, 2004, pp. 100-110. 
ideología oficial de la monarquía, o sea el regalismo. El gobierno de Floridablanca había puesto unas condiciones tácitas para premiar a los jesuitas, aunque a veces unos religiosos consiguieran aprovechar las ineficiencias de la burocracia y el apoyo de algunos funcionarios, como los Comisarios Reales, para presentar obras que se inspiraban en las teorías de la escuela jesuítica.

Se trató, como nos dice Azara con su prosa siempre mordaz, de una forma de recíproca prostitución intelectual, nacida de una situación particular. Eso no quiere decir que algunas obras y sus autores jesuitas no despertasen la atención y la sincera admiración de los manteístas: es el caso de los textos de Juan Andrés, cuya historia de la literatura tuvo mucho éxito y fue adoptada por los Reales Estudios de San Isidro. Pero se trató casi siempre de obras elaboradas por ignacianos, como Juan Francisco Masdeu, que podían contar con patronos importantes e influyentes en la corte o en los ministerios ${ }^{46}$.

Indudablemente, los jesuitas de la Provincia de Aragón se distinguieron por su habilidad en reunir pensiones y honores. Esto se debió no sólo a la capacidad de muchos religiosos de la ex Corona de Aragón para adoptar el mismo «lenguaje» de los ministros, funcionarios e intelectuales manteístas, sino también al éxito que muchos aragoneses, valencianos y catalanes habían conocido en las covachas de las Secretarías y en las instituciones culturales de la Monarquía ${ }^{47}$. La utilización por parte de Floridablanca de esa clase dirigente aragonesa, que se había formado gracias al magisterio directo o indirecto de Gregorio Mayans, como Pérez Bayer, Cerdá, Sempere, Muñoz y otros, facilitó sin duda el éxito literario y económico de los ex jesuitas nacidos en su misma tierra ${ }^{48}$. Pero al final destacan las contradicciones del acercamiento oportunista o de la pacificación entre los jesuitas y el gobierno que les había enviado al exilio: el fracaso de muchas solicitudes de pensión doble o ayudas extraordinarias demuestra el oportunismo de la «generosidad» gubernamental, aunque el empobrecimiento de la comunidad ignaciana exiliada en los años noventa forzó al gobierno a extender la generosidad a todos los expulsos. A lo largo de los años, la pensión vitalicia

46 RodríGUEZ DE CAMPOMANES, Epistolario, vol. 1, pp. 107-108 y 125-126; A. Astorgano ABAJO, «El conde de Aranda y las necesidades económicas del abate Requeno en 1792», en FERRER BENIMELI (dir.), El conde de Aranda, vol. 2, pp. 559-577; A. Astorgano Abajo, «El mecenazgo literario de Campomanes y los jesuitas expulsos», en MATEOs Dorado (ed.), Campomanes, pp. 269-311.

47 A. Mestre Sanchís, Historia, fueros, actitudes políticas. Mayans y la historiografía del siglo XVIII, Oliva, 1970; ID., Despotismo e Ilustración en España, Barcelona - Caracas - México, 1976; P. CERVERA FERri, El pensamiento económico de la Ilustración valenciana, Valencia, 2003.

48 A. Mestre Sanchís, Ilustración y reforma de la Iglesia. Pensamiento político-religioso de don Gregorio Mayans y Siscar (1699-1781), Valencia, 1968; ID., «Divergencias entre ilustrados: el caso Feijoo-Mayans», Studium Ovetense, IV (1976) 275-304; ID., El mundo intelectual de Mayans, Valencia, 1978; ID., Influjo europeo y herencia hispánica. Mayans y la Ilustración valenciana, Valencia, 1987; G. Mayans y Siscar, Epistolario, ed. A. Alemany Peiró, Valencia, 2000, vol. XVII. 
pasó de ser un instrumento de control y se transformó, primero en un estímulo para la colaboración propagandística, y luego, en una forma de limosna.

Después de la caída de Floridablanca, el cambio radical del clima político en España, como consecuencia de la Revolución francesa, sobre todo después de 1793, sentó las bases para una verdadera pacificación entre los expulsos y el gobierno español ${ }^{49}$. Ahora bien, ni siquiera entonces faltaron por parte del gobierno malentendidos y desconfianzas. Sólo la invasión francesa del Estado de la Iglesia y la constitución de los regímenes revolucionarios en el centro de Italia obligaron a Carlos IV a acoger, si bien de mala gana, a los jesuitas en 1798. Pero la nueva expulsión de 1801, a pesar del giro conservador de la política española, probó que la Monarquía y sus ministros, formados ideológicamente durante el reinado de Carlos III, todavía no podían acoger a unos religiosos que habían defendido con firmeza el poder indirecto de los Pontífices.

Como se sabe la Compañía fue admitida en España en 1815, un año después de su restauración gracias a la bula Sollicitudo omnium ecclesiarum del 7 de agosto de 1814: por aquel entonces tan sólo sobrevivían 470 jesuitas españoles expulsos.

\footnotetext{
${ }^{49}$ Sobre el papel desarrollado por los expulsos y por sus discípulos (come el hermano sueco Thjulen) en la producción de la literatura anti-revolucionaria italiana de la época véase A. GUERRA, Il vile satellite del trono. Lorenzo Ignacio Thjulen: un gesuita svedese per la controrivoluzione, Milano, 2004; L. GUERCI, Uno spettacolo non mai più veduto nel mondo. La Rivoluzione francese come unicità e rovesciamento negli scrittori controrivoluzionari italiani (1789-1799), Torino, 2008. 